GOMES GP; GONÇALVES LSA; SEKIYA A; EUZEBIO MP; ROBAINA RR; MARINHO CD. 2016. Registro e proteção de olerícolas no Brasil, período de 1998 a 2014. Horticultura Brasileira 34: 019-026. DOI - http://dx.doi.org/10.1590/S0102-053620160000100003

\title{
Registro e proteção de olerícolas no Brasil, período de 1998 a 2014
}

\author{
Gisely P Gomes $^{1}$; Leandro SA Gonçalves ${ }^{1}$; Alline Sekiya ${ }^{1}$; Milena P Euzebioํㅜ Renata R Robaina ${ }^{2}$; Caillet \\ D Marinho ${ }^{1}$
}

${ }^{1}$ Universidade Estadual de Londrina (UEL), Londrina-PR, Brasil; gipgomes@yahoo.com.br; 1sagrural@yahoo.com; allinesekiya@gmail. com (autor para correspondencia); mpeuzebio@gmail.com; caillet.marinho@yahoo.com.br; ${ }^{2}$ Universidade Estadual do Norte Fluminense (UENF), Campos dos Goytacazes-RJ, Brasil; brrobainarr@yahoo.com.br

\section{RESUMO}

O presente trabalho teve como objetivos realizar um amplo levantamento do número de registros e proteções de diferentes espécies de oleráceas no Ministério da Agricultura, Pecuária e Abastecimento (MAPA) e averiguar a participação de empresas públicas e privadas. Para tanto, foram selecionadas 34 olerícolas de importância econômica e social, sendo essas divididas em tuberosas, herbáceas e frutos. Os dados para estudo foram obtidos a partir do banco de dados do registro nacional de cultivares (RNC) e do serviço nacional de proteção de cultivares (SNPC), disponível em tempo real no site do MAPA. A pesquisa foi realizada entre os períodos de 1998 a 2014. Foram constatados 7174 registros e 147 proteções, sendo as culturas do tomate, Capsicum spp. (pimentões e pimentas), alface e melão com maior número de registros, enquanto para a proteção foram batata e alface. Em relação à participação de instituições privadas e públicas no RNC e SPNC verificou-se um predomínio acentuado das instituições privadas, com 93,23 e $87,75 \%$, respectivamente. O setor público obteve 226 registros e 18 proteções, sendo a Embrapa o destaque, com 57,52 e 72,22\% dos registros e proteções, respectivamente. As parcerias público-privadas tiveram pouca contribuição na geração de novas cultivares. Esse resultado constata a falta de integração entre o setor público e privado, que deveriam atuar, em maiores proporções, conjuntamente, para a conquista de avanços tecnológicos.

Palavras-chave: Melhoramento de plantas, sementes, registro nacional de cultivares (RNC), serviço nacional de proteção de cultivares (SNPC).

\begin{abstract}
Registration and protection of vegetables in Brazil between 1998 and 2014

This study aimed to realize a broad survey of the registry and protection numbers concerning different vegetables species in the Ministério da Agricultura Pecuária e Abastecimento - MAPA (Brazilian Ministry of Agriculture, Livestock and Food Supply) and to investigate the participation of public and private institutions. Therefore, 34 vegetable crops of economic and social importance were selected, these being divided into tuberous, herbaceous (leaves, flowers and stems) and fruits. Data for the study were obtained from the Registro Nacional de Cultivares - RNC (Brazilian National Register of Cultivars) and the Serviço Nacional de Proteção de Cultivares - SNPC (Brazilian National Service of Plant Variety Protection, available in real time the MAPA site. The survey was carried out between 1998 and 2014. We verified 7174 registry and 147 protections, tomato, Capsicum spp. (sweet and chili peppers), lettuce and melon presenting the highest number of records, while the potato and lettuce had the highest protection numbers. In relation to the participation of private and public institutions in the RNC and SPNC, there was a marked predominance of private institutions was observed, with 93.23 and $87.75 \%$, respectively. The public sector obtained 226 registries and 18 protections, Embrapa (Brazilian Agricultural Research Corporation) being highlighted with 57.22 and $72.22 \%$ of the registries and protections, respectively. Publicprivate partnerships have had little contribution in the generation of new cultivars. This result finds the lack of integration between the public and private sector, which should work in greater proportions jointly for achieving technological breakthroughs.
\end{abstract}

Keywords: Plant breeding, seeds, national register of cultivars (RNC), national service of plant variety protection (SNPC).

(Recebido para publicação em 16 de março de 2015; aceito em 18 de setembro de 2015) (Received on March 16, 2015; accepted on September 18, 2015)

A olericultura desempenha um importante papel sócio econômico no Brasil, fornecendo alimento e gerando emprego e renda à população. Segundo estimativa da Associação Brasileira do Comércio de Sementes e Mudas (ABCSEM), em 2012, considerando 18 espé- cies hortícolas, o volume total produzido foi de 19,62 milhões de toneladas, com uma área cultivada de 656 mil hectares e gerando dois milhões de empregos diretos (ABCSEM, 2014).

O mercado de sementes de olerícolas vem crescendo e evoluindo ao longo dos últimos anos, tendo em 2012, atingido um faturamento de R\$ 475 milhões (ABCSEM, 2014). Esse mercado vem se tornando altamente concentrado e competitivo, no qual verifica-se a venda de tradicionais empresas brasileira às multinacionais e as recentes fusões 
dessas últimas (Carvalho et al., 2009; Marinho et al., 2011).

Com o objetivo de estabelecer mecanismos para organização, sistematização e controle da produção e comercialização de sementes e mudas, o Ministério da Agricultura, Pecuária e Abastecimento (MAPA) instituiu por meio da Portaria ${ }^{\circ} 527$, de 30 de dezembro de 1997, o Registro Nacional de Cultivares (RNC). Atualmente, o RNC é regido pela Lei de Sementes $n^{\circ}$ $10.711 / 03$, tendo princípio que a geração de novas cultivares se traduz em altas tecnologias transferidas para o agronegócio, indispensáveis ao sucesso deste, pelo aumento da produtividade agrícola e da qualidade dos insumos e dos produtos deles derivados (BRASIL, 2014).

O RNC é de elevada importância para os programas de melhoramento de plantas, pois garante a identidade genética e qualidade varietal das cultivares, resguarda as cultivares melhoradas contra a degradação decorrentes de misturas mecânicas, cruzamentos, troca de nomes e outras ocorrências acidentais (Carvalho et al., 2009). Um dos requisitos para inscrição de uma cultivar no RNC é que a mesma possua um Valor de Cultivo e Uso (VCU), identificado e comprovado por experimentos, seguindo critérios mínimos estabelecidos para cada espécie. O VCU pode ser determinado pelo próprio requerente do registro ou por uma instituição de pesquisa e desenvolvimento pública ou privada, por meio de contrato ou convênio (BRASIL, 2014).

A proteção de cultivares, regida pela Lei $n^{\circ}$ 9.456/97 e coordenada pelo Serviço Nacional de Proteção de Cultivares (SNPC), tem como principio fortalecer e padronizar os direitos de propriedade intelectual. A proteção dos direitos intelectuais sobre a cultivar é efetuada mediante a concessão de um certificado de proteção de cultivares, sendo considerado um bem móvel e a única forma de proteção das espécies superiores de plantas (BRASIL, 2014). A duração da proteção de uma cultivar vigora a partir da data de concessão do Certificado Provisório de Proteção, pelo prazo de 15 anos, com exceção das videiras e árvores (frutíferas, florestais e ornamentais), inclusive, em cada caso, o seu porta-enxerto, para as quais a du- ração será de 18 anos (BRASIL, 2014).

Para a proteção é necessária a comprovação das características da cultivar por meio de ensaios de Distinguibilidade, Homogeneidade e Estabilidade (DHE), que só podem ser realizados para as espécies que possuem descritores morfológicos publicados no Diário Oficial pelo MAPA. Atualmente, os descritores publicados para as olerícolas são para as seguintes espécies: Abóbora (Cucurbita spp.), Alface (Lactuca sativa), alho (Allium sativum), cebola (Allium cepa), cenoura (Dacus carota), ervilha (Pisum sativum), estévia (Stevia rebaudiana), melancia (Citrullus lanatus), melão (Cucumis melo), morango (Fragaria spp.), pimentão/pimenta (Capsicum spp.), Quiabo (Abelmoschus esculentus) e tomate (Solanum lycopersicum) (Santos et al., 2012; BRASIL, 2014).

Marinho et al. (2011), realizando levantamento de registros e proteções de 27 principais espécies agrícolas produzidas no Brasil, no período de 1998 a 2011, verificaram 2513 registros para sete olerícolas (tomate, Capsicum spp., alface, cenoura, batata, beterraba e batata-doce), enquanto para proteção foram encontrados 103 para quatro olerícolas (batata, alface, cenoura e pimenta). A grande maioria dos registros e proteções foi proveniente de instituições privadas. Sendo assim, o presente trabalho teve como objetivos realizar um amplo levantamento do número de registros e proteções de diferentes espécies de oleráceas no MAPA e averiguar a participação de empresas privadas e publicas.

\section{METODOLOGIA}

Os dados para estudo foram obtidos a partir do banco de dados do registro nacional de cultivares (RNC) e do serviço nacional de proteção de cultivares (SNPC), disponível em tempo real no site do Ministério da Agricultura, Pecuária e Abastecimento (MAPA) (http:// www.agricultura.gov.br).

Foram agrupadas as inscrições e proteções de acordo com a natureza das instituições obtidas, separados em instituição privada (inclui também pessoa física), instituições públicas, parcerias público/privadas e não identificadas. As informações foram inseridas em tabelas e analisadas usando a Microsoft Office Excel 2007, e os dados foram apresentados utilizando estatística descritiva. Os dados foram divididos em nome das cultivares, mantenedor e data.

Para selecionar as espécies para inclusão neste estudo, foi levada em conta a importância econômica e social das olerícolas. Foram selecionadas 34 olerícolas que foram divididas em: tuberosas, herbáceas e frutos. Por conseguinte, as espécies que foram consideradas: (1) Tuberosas: Rabanete (Raphanus sativus), Nabo (Brassica napus), Batata doce (Ipomoea batatas), Beterraba (Beta vulgaris), Cenoura (Daucus carota), Mandioquinha-salsa (Arracacia xanthorrhiza), Batata(Solanum tuberosum), Taro (Inhame) (Colocasia esculenta), Alho (Allium sativum) e Cebola (Allium cepa); (2) herbáceas (folha, flor e haste): Alface (Lactuca sativa), Almeirão (Cichorium intybus), Couve-comum (Brassica oleracea var. acephala), Espinafre (Tetragonia tetragonoides), Rúcula (Eruca sativa), Repolho (Brassica oleracea var. capitata), Chicória (Cichorium endivia), Couve-flor (Brassica oleracea var. botrytis), Brócolis (Brassica oleracea var. italica), Agrião (Nasturtium officinale), Aipo/ Salsão(Apium graveolens) e Cebolinha (Allium fistulosum); (3) Frutos: Ervilha (Pisum sativum), Abóbora (Cucurbita moschata e C. máxima), Berinjela (Solanum melongena), Jiló (Solanum gilo), Pimentão/pimenta (Capsicum spp.), Pepino (Cucumis sativus), Quiabo (Abelmoschus esculentus), Tomate (Solanum lycopersicum), Melancia ( $\mathrm{Ci}$ trullus lanatus), Melão (Cucumis melo), Abobrinha (Cucurbita pepo) e Morango (Fragaria spp.). O período de pesquisa na pagina virtual CultivarWeb do site do MAPA, foi realizada no período de 1998 a 31 de dezembro de 2014.

\section{REGISTROS}

No geral, foram verificados 7174 registros para as 34 espécies oleráceas estudadas, sendo os maiores números registrados para tomate, Capsicum spp., alface, melão e cebola, com 20,44, 
$10,68,8,43,8,20$ e $5,52 \%$, respectivamente, enquanto o menor número foi verificado para mandioquinha e inhame com apenas três registros cada.

Em relação à participação de instituições privadas e públicas no registro nacional de cultivares (RNC), verificou-se predomínio acentuado das instituições privadas, com 93,23\%. Registros não identificados (cultivares com registro, porém o mantenedor não se identificou) e instituições públicas obtiveram 3,53 e $3,15 \%$, respectivamente, enquanto parceria entre instituições públicas e privadas foram observadas apenas para seis registros $(0,09 \%)$, sendo duas para cultura da cebola (Embrapa/Feltrin e Embrapa/Hortec), e uma para batata (Embrapa/Fundação da Universidade de Passo Fundo), alface (IAC/Horticeres), abóbora (Embrapa/Hortec) e morango (IAC/Multiplanta) (Tabela 1).

$\mathrm{O}$ número de parcerias entre instituições públicas e privadas identificadas para as oleráceas é subestimado em virtude de algumas instituições públicas, como por exemplo, a Embrapa, realizarem parcerias nas fases finais de pesquisa e na colocação de tecnologias no mercado. Esses acordos, geralmente, estabelecem que o parceiro privado aporte com recursos na pesquisa e, em contrapartida, recebe o direto de ser licenciado de forma exclusiva para explorar esses materiais, conforme verificado para algumas cultivares de pimenta e de tomate e que não foram verificados no site do MAPA (Castro et al. 2011; Embrapa, 2014). Marinho et al. (2011), no levantamento de registros e proteção de 27 espécies agrícolas, verificaram 7262 registros, no qual, apenas 35 foram identificadas parcerias entre instituições públicas e privadas, sendo 31 registros para soja (Glycine max), três para banana (Musa spp.) e um para arroz (Oryza sativa).

O baixo número de registros verificados pelas instituições públicas se deve principalmente à falta de incentivo das instituições de fomento (federais e estaduais) e no desenvolvimento de novas tecnologias. Na maioria das vezes a aprovação de projetos está relacionada com o nível de publicação do pesquisador, incentivando os mesmos a migrarem para áreas de biotecnologia. Segundo levantamento realizado por Ramalho et al. (2010) em relação ao número de dissertações e/ou teses defendidas nos seis principais programas de pós-graduação em genética e melhoramento no Brasil (ESALQ, UNESP, UFV, UFLA, UEM e UENF), verificaram uma tendência de diminuição do número de trabalhos que envolvem diretamente o melhoramento, visando a obtenção de cultivares em decorrência do acréscimo de pesquisas nas áreas de biotecnologia e de recursos genéticos.

Por grupo de olerícolas, verificou-se uma maior participação do setor público para espécies tuberosas, com 8,33\%, seguido dos grupos frutos e herbáceas (folha, flor e haste), com 2,69\% e 0,48\%, respectivamente (Tabela 1). O grupo das tuberosas obteve 1237 registros, sendo os maiores números encontrados para cebola, cenoura e batata, com 396, 335 e 195, respectivamente. Pelo levantamento realizado por Marinho et al. (2011), no período de 1998 a 2011, foram verificados 258 e 149 registros para cenoura e batata, respectivamente, um incremento de $29,84 \%$ para cenoura e $30,87 \%$ para batata.

As instituições públicas obtiveram 103 registros para o grupo das tuberosas, distribuídos nas culturas batata-doce (27), batata (26), cebola (24), alho (15), cenoura (4), mandioquinha-salsa (3), inhame (3) e nabo (1). Batata-doce, mandioquinha, inhame e alho foram desenvolvidos exclusivamente pelo setor público. Entretanto, na cultura do alho, em 27 registros não foi identificada a procedência (Figura 1).

A cultura do alho possui um grande potencial no país, no qual são consumidos 26,4 milhões de caixas (10 $\mathrm{kg}$ ) por ano. Contudo, a área produtora no Brasil é de apenas 10 mil hectares representando $33 \%$ do abastecimento interno. O restante é importado da China (42\%) e Argentina (25\%) (Anuário Brasileiro de Hortaliças, 2013). Portanto, há necessidades de politicas públicas de proteção da produção nacional e de programas de melhoramento, no qual $85 \%$ das cultivares registradas foram realizadas antes de 2000 . As instituições públicas envolvidas nos registros para cultura do alho foram Empresa de Pesquisa Agropecuária e Extensão Rural de Santa Catarina (EPAGRI), IAC e Embrapa com dez, três e dois registros, respectivamente.

Para batata-doce os registros foram efetuados pela Universidade Federal de Tocantins (UFT), Embrapa, EPAGRI e

Tabela 1. Proporções de registros de olerícolas (tuberosas, herbáceas e frutos) no Ministério da Agricultura, Pecuária e Abastecimento (MAPA) de acordo com a natureza do obtentor no período de 1998 a 2014 \{proportion of vegetables registrations (tuberous, herbaceous and fruits) in the Ministry of Agriculture, Livestock and Food Supply (MAPA) according to the nature of the obtainer for the period from 1998 to 2014\}. Londrina, UEL, 2014.

\begin{tabular}{|c|c|c|c|c|c|c|c|c|}
\hline \multirow{2}{*}{ Obtentor $^{1}$} & \multicolumn{2}{|c|}{ Total } & \multicolumn{2}{|c|}{ Tuberosas } & \multicolumn{2}{|c|}{ Herbáceas } & \multicolumn{2}{|c|}{ Frutos } \\
\hline & $\left(\mathrm{n}^{\circ}\right)$ & $(\%)$ & $\left(n^{0}\right)$ & $(\%)$ & $\left(\mathrm{n}^{0}\right)$ & $(\%)$ & $\left(\mathrm{n}^{\circ}\right)$ & $(\%)$ \\
\hline IPR & 6688 & 93,23 & 1038 & 83,91 & 1610 & 97,05 & 4040 & 94,43 \\
\hline IPU & 226 & 3,15 & 103 & 8,33 & 8 & 0,48 & 115 & 2,69 \\
\hline IPR/IPU & 6 & 0,08 & 3 & 0,24 & 1 & 0,06 & 2 & 0,05 \\
\hline $\mathrm{NI}$ & 254 & 3,54 & 93 & 7,52 & 40 & 2,41 & 121 & 2,83 \\
\hline Total & 7174 & 100 & 1237 & 100 & 1659 & 100 & 4278 & 100 \\
\hline
\end{tabular}

${ }^{1} \mathrm{IPR}=$ Instituições privadas/pessoa física (private institutions); IPU= Instituições públicas (public institutions); IPR/IPU= parceria entre instituições privadas e públicas (private/public partnership); e NI= não identificado (unidentified). 


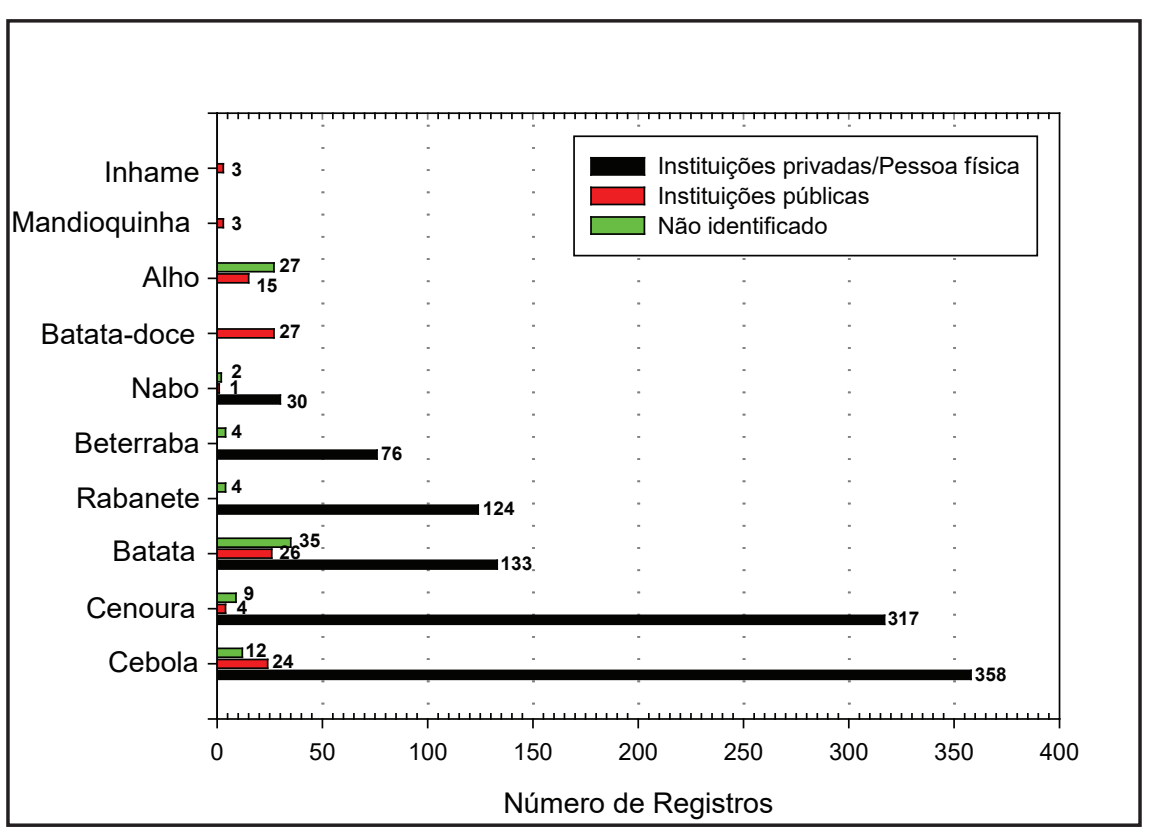

Figura 1. Histograma de registros de olerícolas tuberosas no Ministério da Agricultura, Pecuária e Abastecimento (MAPA) de acordo com a natureza do obtentor no período de 1998 a 2014 \{histogram of the tuberous vegetables in the Ministry of Agriculture, Livestock and Food Supply (MAPA) according to the nature of the obtainer for the period from 1998 to 2014\}. Londrina, UEL, 2014.

Instituto Agronômico do Paraná (IAPAR), no qual, verificaram-se dez, nove, seis e dois registros, respectivamente. Em relação à mandioquinha-salsa, os registros das cvs. 'Amarela do Senador Amaral' (registrada em 2000), 'BRS Catarina 64'e 'BRS Rubia 41' (ambas registrada em 2014) foram realizados pela Embrapa, enquanto para as cvs. de inhame/taro ('Chinês', 'Macaquinho' e 'São bento', registradas em 2008) foram efetuados pelo Instituto Capixaba de Pesquisa, Assistência Técnica e Extensão Rural (INCAPER).

Para as culturas da batata, cebola e cenoura verificou-se o envolvimento de diferentes empresas privadas (23, 33 e 26 , respectivamente) no RNC, sendo que para cultura da batata não foi verificado predomínio de empresas no número de registros, enquanto, para cebola houve predomínio das empresas Agristar, Feltrin, Monsoy, Nunhems e Sakata (49,49\% dos registros), e para cenoura o predomínio da Agristar, Bejo sementes, Nunhems e Sakata (51,94\% dos registros). Estas espécies representam um importante setor da olericultura brasileira, com uma área plantada de 209,5 mil hectares $(127,19,57,35$ e 25,00 mil hectares, respectivamente) e uma produção de 5,52 milhões $\mathrm{t}(3,38$, 1,36 e 0,78 milhões $t$, respectivamente) em 2012 (Anuário Brasileiro de Hortaliças, 2013).

Dentro do setor público, quatro instituições foram envolvidas no registro da batata (Embrapa, IAC, IAPAR e Epagri) e da cebola [Embrapa, Epagri, Instituto Agronômico de Pernambuco (IPA) e Fundação Estadual de pesquisa Agropecuária )FEPAGRO)], e apenas a Embrapa no registro da cenoura, com as cultivares 'Alvorada', 'BRS Esplanada', 'BRS Planaltina', 'BRS Planalto' e 'Kuronan'. A cv. 'Brasília', desenvolvida em 1981 pela Embrapa e pela Escola Superior de Agricultura Luiz de Queiroz (ESALQ-USP), considerada uma das cultivares de cenoura mais importante no país, no qual, impulsionou a produção interna e regularizou o abastecimento (Grangeiro et al., 2012), está registrada, a sua denominação, pelas empresas Feltrin, Hortec, Horticeres e VidaSul (MAPA, 2014).

As culturas do rabanete e beterraba obtiveram 128 e 80 registros, respectivamente, sendo todos pertencentes a instituições privadas (Figura 1). Entre as empresas, Feltrin, Agristar e Sakata obtiveram o maior número de registros com 29, 27 e 22 , respectivamente. O nabo possui 33 registros, tendo apenas um registro de uma empresa pública [Departamento de Sementes, Mudas e Matrizes (DSMM/CATI), cultivar 'CATI AL 1000']. Entre as empresas privadas, o maior número de registros foi da Sakama, Feltrin e Isla, com sete, seis e cinco, respectivamente.

Para o grupo das herbáceas (folhas, flores e haste) verificou-se 1659 registros, sendo os maiores números encontrados para alface, repolho e couve-flor, com 605, 266 e 259, respectivamente. Esse grupo representa um importante papel na cadeia do agronegócio das olericolas. Segundo a Companhia Nacional de Abastecimento (CONAB), em 2012, as 23 principais Centrais de Abastecimento Brasileiras (CEASA) comercializaram 522 mil toneladas de olerícolas do subgrupo folha, flor e haste, gerando uma receita de aproximadamente $\mathrm{R} \$ 2$ bilhões (Anuário Brasileiro de Hortaliças, 2013). As olerícolas mais vendidas foram repolho (240 mil t), couve-flor (85 mil t), alface (79 mil t), brócolis (29 mil t), acelga (15,6 mil t), couve-comum ( 8 mil t $)$, couve-chinesa (6,3 mil t), cebolinha (6 mil t), escarola (5,7 mil t) e agrião (5,7 mil t) (Anuário Brasileiro de Hortaliças, 2013).

Apesar da importância econômica das olerícolas herbáceas, as instituições públicas obtiveram apenas oito registros, distribuídos nas culturas da alface, brócolis e repolho, com cinco, dois e um, respectivamente (Figura 2). Na cultura da alface, os registros foram obtidos pela Epagri (cv. 'Empasc 357(litoral)', registrada em 1998) e pela Universidade Federal de São Carlos (UFSCar) (cv. 'Brunela', registrada em 2012, e cvs. 'Crocantela', 'Romanela' e 'Rubinela', registradas em 2013). Para brócolis e repolho, a instituição pública envolvida foi a Embrapa com as cvs. 'Ramoso Brasili' e 'Ramoso de Brasília' (ambas registradas em 2000) para brócolis, e cv. 'União' (registrada em 2000) para repolho.

Entre as instituições privadas, 33 empresas estiveram envolvidas nos registros da cultura da alface, sendo as empresas Sakata, Agristar, Monsoy e Feltrin com maior número $(81,74,48$ e 45 registros, respectivamente). Entre 


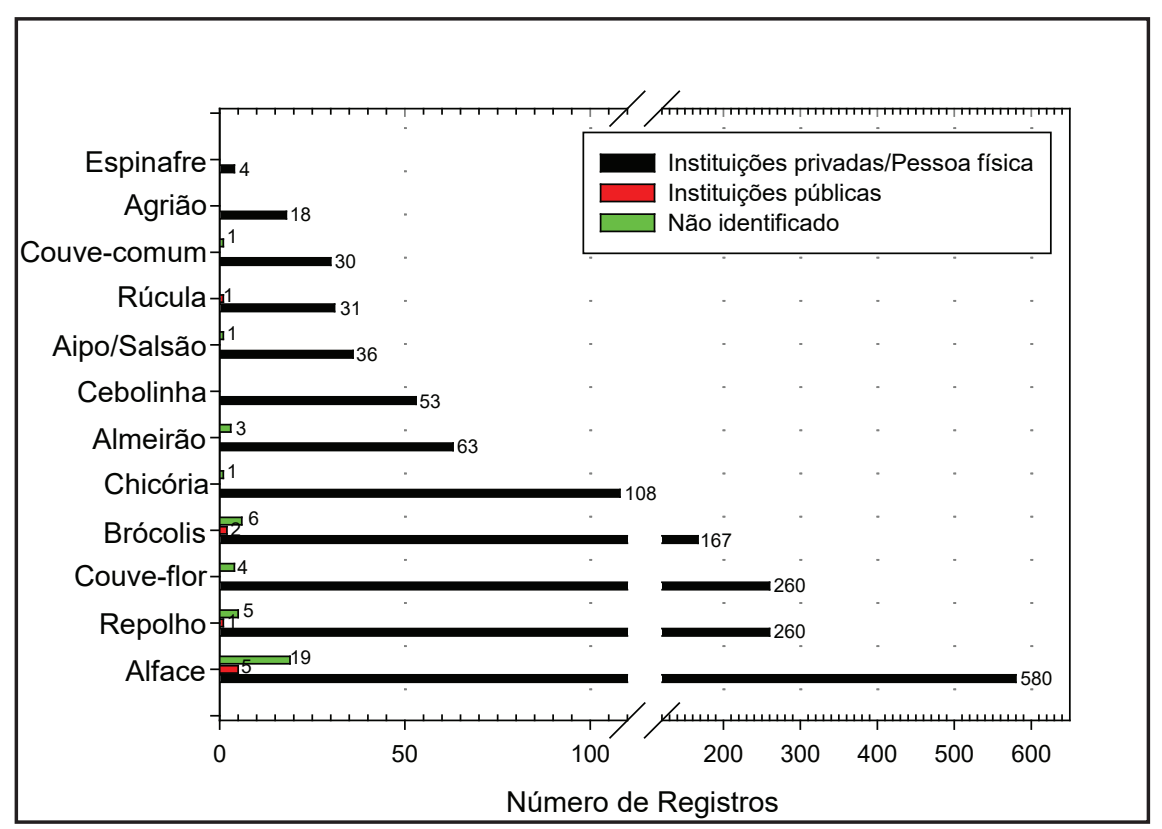

Figura 2. Histograma de registros de olerícolas herbáceas no Ministério da Agricultura, Pecuária e Abastecimento (MAPA) de acordo com a natureza do obtentor no período de 1998 a 2014 \{histogram of the herbaceous vegetables in the Ministry of Agriculture, Livestock and Food Supply (MAPA) according to the nature of the obtainer for the period from 1998 to 2014\}. Londrina, UEL, 2014.

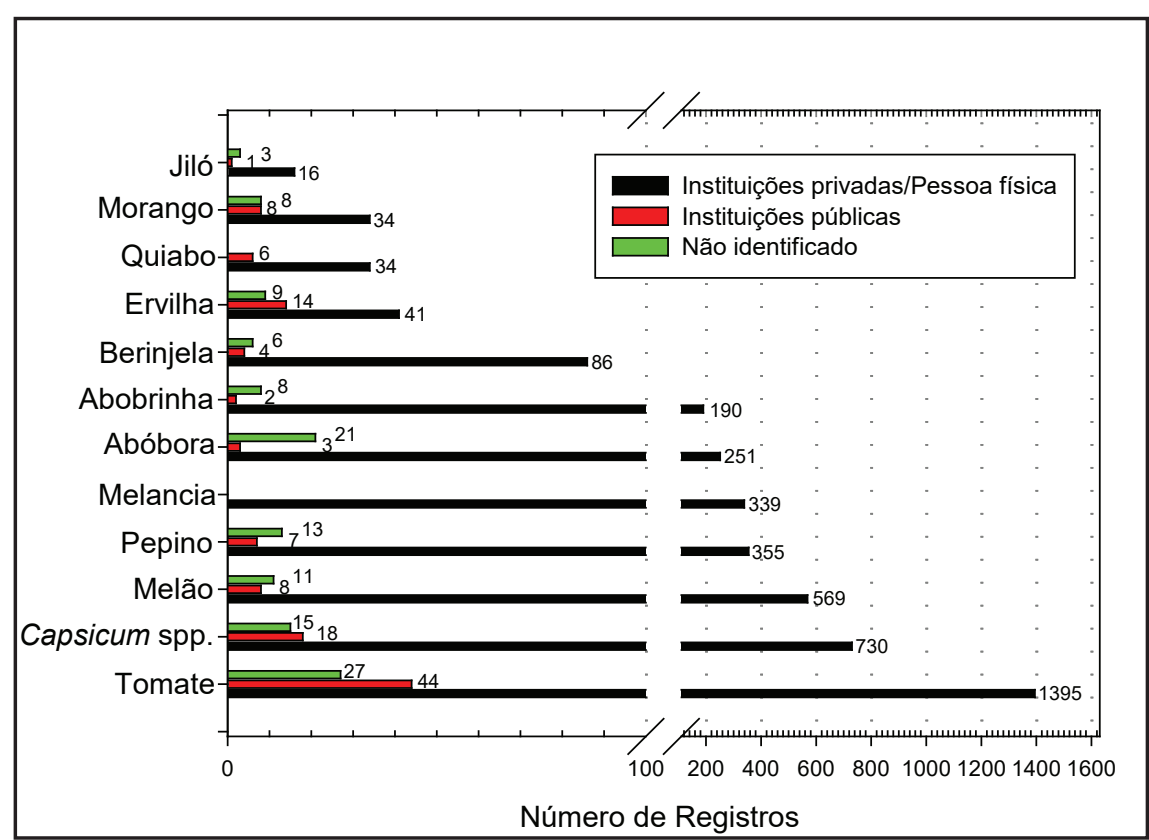

Figura 3. Histograma de registros de olerícolas frutos no Ministério da Agricultura, Pecuária e Abastecimento (MAPA) de acordo com a natureza do obtentor no período de 1998 a 2014 \{histogram of the fruits vegetables in the Ministry of Agriculture, Livestock and Food Supply (MAPA) according to the nature of the obtainer for the period from 1998 to 2014\}. Londrina, UEL, 2014.

as brássicas (couve-comum, couve-flor, repolho e brócolis) 37 empresas obtiveram registros, sendo também as empresas Sakata, Agristar, Monsoy e Feltrin com maior número $(157,59,67$ maior número de registros (65), seguida pelas empresas Agristar e Feltrin, com 35 e 32 registros, respectivamente.

Para o grupo dos frutos verificou-se 4277 registros, sendo o tomate com maior número (1466), seguido por Capsicum spp. (pimentões e pimentas), melão e pepino, com 763, 588 e 375 registros, respectivamente. Pelo levantamento realizado por Marinho et al. (2011), foram verificados $1044 \mathrm{e}$ 557 registros para tomate e Capsicum spp., respectivamente, um incremento de $40,42 \%$ para tomate e $36,98 \%$ para Capsicum spp.

As instituições públicas obtiveram 115 registros, distribuídos praticamente em todas as culturas, exceto as cultivares de melancia que foram exclusivamente registradas por empresas do setor privado (Figura 3). O tomate obteve 44 registros de empresas públicas, sendo a maioria pertencente à Embrapa, com 34 registros, seguido pelo IPA, IAC e Universidade Federal de Lavras (UFLA), com cinco, quatro e um registros, respectivamente.

Em relação a instituições privadas, 42 empresas requereram registros para cultura do tomateiro, sendo a maioria pertencente à Sakata, Agristar, Blue Seeds e Monsoy, com 282, 202, 188 e 123 registros, respectivamente. No Brasil a tomaticultura exerce um importante papel no agronegócio, sendo dividida entre o produto destinado à mesa $\mathrm{e} o$ encaminhado ao processamento industrial, no qual, esse último segmento movimenta mais de $\mathrm{R} \$ 2,6$ bilhões por ano (Anuário Brasileiro de Hortaliças, 2013). De acordo com o Levantamento Sistemático da Produção Agrícola (LSPA), a tomaticultura obteve uma produção de 3,99 milhões de t em uma área plantada de 60,52 mil hectares em 2013 (LSPA, 2014).

Para Capsicum spp., que inclui pimenta e pimentão, obteve 648,60 , 42 e 13 registros para $C$. annuum, $C$. frutescens, C. chinense e C. baccatum, respectivamente. Entre as instituições públicas, 18 registros foram identificados, sendo 15 pertencentes à Embrapa [C. baccatum ('Brs Coral', 'Brs Itamira', 'Brs Manuela', 'Brs Ouro' e 'Brs Mari'); C. chinense ('Brs Jandaia', 'Brs Juruti', 'Brs Moema' e 'Brs Seriema'); 
Tabela 2. Número de proteção de olerícolas no Ministério da Agricultura e Pecuária e Abastecimento (MAPA) no período de 1998 a 2014 \{protection numbers of vegetables in the Ministry of Agriculture, Livestock and Food Supply (MAPA), period 1998 to 2014). Londrina, UEL, 2014.

\begin{tabular}{|c|c|c|c|c|c|c|c|c|c|c|c|c|c|c|c|c|c|c|}
\hline \multirow{2}{*}{ Espécies } & \multicolumn{17}{|c|}{ Ano } & \multirow{2}{*}{ Tota } \\
\hline & 98 & 99 & 00 & 01 & 02 & 03 & 04 & 05 & 06 & 07 & 08 & 09 & 10 & 11 & 12 & 13 & 14 & \\
\hline Batata & 0 & 2 & 3 & 1 & 2 & 2 & 4 & 2 & 5 & 3 & 2 & 4 & 1 & 3 & 13 & 7 & 3 & 57 \\
\hline Cenoura & 0 & 0 & 0 & 0 & 0 & 0 & 0 & 3 & 0 & 0 & 0 & 0 & 0 & 1 & 1 & 0 & 0 & 5 \\
\hline Pimenta & 0 & 0 & 0 & 0 & 0 & 0 & 0 & 0 & 0 & 0 & 0 & 0 & 2 & 0 & 0 & 0 & 0 & 2 \\
\hline Cebola & 0 & 0 & 0 & 0 & 0 & 0 & 0 & 0 & 1 & 0 & 0 & 0 & 0 & 1 & 1 & 0 & 0 & 3 \\
\hline Quiabo & 0 & 0 & 0 & 0 & 0 & 0 & 0 & 0 & 0 & 0 & 0 & 0 & 0 & 0 & 0 & 0 & 2 & 2 \\
\hline Ervilha & 0 & 0 & 0 & 0 & 0 & 0 & 0 & 0 & 0 & 2 & 0 & 0 & 0 & 0 & 0 & 0 & 0 & 2 \\
\hline Alface & 0 & 0 & 0 & 0 & 1 & 1 & 1 & 6 & 3 & 2 & 10 & 6 & 1 & 6 & 3 & 2 & 14 & 56 \\
\hline Morango & 0 & 0 & 0 & 0 & 0 & 0 & 2 & 1 & 0 & 0 & 1 & 1 & 1 & 4 & 2 & 1 & 1 & 14 \\
\hline Tomate & 0 & 0 & 0 & 0 & 0 & 0 & 0 & 0 & 0 & 0 & 0 & 0 & 0 & 0 & 0 & 2 & 0 & 2 \\
\hline Melão & 0 & 0 & 0 & 0 & 0 & 0 & 0 & 0 & 0 & 0 & 0 & 0 & 0 & 0 & 1 & 1 & 2 & 4 \\
\hline
\end{tabular}

C. frutescens ('Brs Avaí'); e C.annuum ('Brs Brasilândia', 'Brs Ema', 'Brs Garça', 'BrsSarakura' e 'Brs Vilma')], dois ao IAC [C. annuum ('Agronômico 10G' e 'IAC Ubatuba')] e uma à UFLA [C. annuum ('Pep 16')]. Em relação às instituições privadas, 37 empresas requereram registros, sendo a maioria pertencente à Sakata e Agristar, com 168 e 100 registros, respectivamente.

As duas outras solanáceas (berinjela e jiló) que apresentam uma menor expressão econômica quando comparados com tomate e Capsicum spp., obtiveram 96 e 20 registros, respectivamente, tendo apenas cinco cultivares registradas por instituições públicas [berinjela ('Ciça', 'híbrida Ciça F,', 'CNPH 006' e 'CNPH 791 ' pela Embrapa); e jiló ('MN8' pela UFLA)]. Dezenove empresas privadas estiveram envolvidas nos registros dessas culturas, sendo a Agristar, Sakama e Sakata com maior número, com 23, 15 e 12 registros, respectivamente.

O melão e a melancia, líderes entre as olerícolas exportadas (181,77 e 33,54 mil t em 2012, respectivamente) (Anuário Brasileiro de Hortaliças, 2013), obtiveram 588 e 339 registros, respectivamente. Contudo, apenas oito registros foram verificados pelas instituições públicas para cultura do meloeiro, sendo quatro pela Embrapa (cvs. 'Brs Araguaia', 'EHMEL 200910', 'EHMEL 20095' e 'Eldorado') e quatro pela Epagri (cvs. 'Epagri 357', 'Epagri
358', 'Epagri 359'e 'Epagri 360’). Esse resultado é corroborado com a maioria das olerícolas, no qual, percebe-se o grande domínio do setor privado no desenvolvimento de cultivares, sendo quase uma exclusividade. Entre as instituições privadas, Sakata, Monsoy, Syngenta, Agristar e Nunhems obtiveram o maior número, com 195, 134, 97, 84 e 73 registros, respectivamente.

Para as cucurbitáceas (abóbora e abobrinha) foram verificados $275 \mathrm{e}$ 200 registros, respectivamente, sendo cinco provenientes de instituições públicas. Para abóbora os registros das instituições públicas foram obtidos pela Embrapa (cvs. 'Brs Brasileirinha' e 'Brs Tortei') e pelo IAC [cv. 'Coroa (IAC 1616)'], enquanto para abobrinha foram exclusivamente da Embrapa (cvs. 'Brs Estrela' e 'Brs Linda'). O maior número de registros das instituições privadas foi obtido pela Sakata (141), seguido pela Agristar e Monsoy, com 56 e 51 registros, respectivamente.

O pepino obteve 375 registros, sendo sete provenientes de instituições públicas [Embrapa (cvs. 'Anápolis 796', 'Anápolis 798', 'Brs Curumim', 'Colônia', 'Guaíra' e 'Shibata'), e IAC (cv. 'Okusankichi')], 13 não identificados e 355 provenientes de instituições privadas. Trinta e cinco empresas privadas estiveram envolvidas nos registros do pepino, sendo que a Monsoy, Sakata e Agristar obtiveram o maior número, com 51, 51 e 49 registros, respectivamente.

A ervilha, o morango e o quiabo obtiveram 64, 51 e 40 registros, respectivamente, sendo 28 provenientes de instituições públicas, no qual, 17 foram registrados pela Embrapa (ervilha: 13 e morango: 4), dez pelo IAC (morango: 4 e quiabo: 6) e um pelo IAPAR (ervilha). Entre as instituições privadas, dez empresas obtiveram registros para o morango, enquanto para ervilha e quiabo foram 13 e 12 empresas, respectivamente.

\section{PROTEÇÃO}

O Sistema Nacional de Proteção de Cultivares possui 147 proteções, para dez espécies oleráceas (Tabela 2). Dessas, 18 cultivares foram provenientes de instituições públicas, sendo 12 pertencentes à Embrapa, quatro à UFSCAR e uma à EPAGRI e à parceria entre Embrapa/IAPAR.

Das cultivares protegidas pela Embrapa, quatro foram para batata (cvs. 'Brs Elisa', 'Brs Ana', 'Brs Clara', 'Brs Elisa') e Embrapa/Iapar ('Brs IPR Bel'), protegidas em 2000, 2007, 2011 e 2012, respectivamente, duas para cebola (cvs. 'Brs Alfa São Francisco' e 'Brs 367') protegidas em 2006 e 2012, respectivamente, duas para melão (cvs. 'EHMEL 200910' e 'EHMEL20095'), 
ambas protegidas em 2014, duas para pimenta (C. annuum) (cvs. 'Brs Garça' e 'Brs Sarakura') ambas protegidas em 2010, duas para tomate (cvs. 'L512' e 'L635') ambas protegidas em 2013 e uma para cenoura (cv. 'Brs Planalto') protegida em 2011. A UFSCAR possui quatro proteções para alface (cvs. 'Brunela', 'Crocantela', 'Romanela' e 'Rubinela') protegidas em 2014, enquanto a EPAGRI possui uma proteção para cebola (cv. 'SCS366 Poranga') protegida em 2012.

Em relação ao setor privado, 14 instituições requereram proteção para batata e sete para alface. As empresas Agrico U.A, HZPC Holland B.V e Germicopa SAS $(11,11$ e 8 , respectivamente) obtiveram predomínio no número de cultivares protegidas para batata, enquanto para a alface o predomínio foi da Sakata (23), seguida pela Monsoy e Hortec, com oito e sete cultivares protegidas, respectivamente. Para o morango, os setores privados envolvidos foram University of California, Planasa, Florida Foundation Seeds Producers e Lassen Canyon Nursey, com sete, quatro, dois e uma cultivares protegidas, respectivamente, enquanto para o quiabo e a ervilha as proteções foram realizadas pela Sakata e para cenoura pela Monsoy e Isla.

Conforme verificado pelo RNC, houve também um predomínio das instituições privadas na proteção de cultivares, com $87,75 \%$, indicando o amplo domínio do setor privado no mercado de sementes de olerícolas. Esse mercado vem se tornado altamente concentrado e competitivo, no qual, verifica-se a venda de tradicionais empresas brasileiras às multinacionais e as recentes fusões dessas últimas (Carvalho et al., 2009; Marinho et al., 2011).

Entre as instituições públicas, a Embrapa obteve o maior número de registros e proteção, com 57,52 e 72,22\%, respectivamente. Um ponto a ser destacado, entre as dez Universidades (UEM, UENF, UFG, UFLA, UFPI, UFRPE, UFV, UNEMAT, UNESP e USP) que possuem programas de pós-graduação em melhoramento de plantas, somente a
UFLA possui registro para as olerícolas estudadas.

Nesse contexto há necessidade de incentivos do setor público para o desenvolvimento de programas de melhoramento de olerícolas e a sua integração com o setor privado visto o elevado potencial do mercado de sementes. Essas parcerias são vantajosas tanto para o setor público quanto para as empresas privadas, em virtude principalmente, da escassez cada vez maior de recursos públicos para pesquisa e desenvolvimento nos centros de pesquisa (Federais e Estaduais) e Universidades.

Nas parcerias, geralmente, as instituições públicas fornecem os serviços intelectual dos pesquisadores, infraestrutura de pesquisa tais como laboratórios, casa de vegetação, campos experimentais e um amplo reservatório de genes nos seus respectivos bancos de germoplasma, obtidos ao longo dos anos. Em contrapartida, as instituições privadas fornecem um aporte para as atividades de pesquisa, desenvolvimento e transferência de tecnologia, objetivando que os resultados dos esforços conjuntos de pesquisa e desenvolvimento se transformem em inovação tecnológica.

Segundo Fuck \& Bonacelli (2011), o Brasil criou instrumentos importantes para ampliar a parceria público-privada, como por exemplo, a Lei de Inovação e à criação de Empresas de Propósito Específico (EPEs). Entretanto, o modelo jurídico anacrônico de boa parte das instituições públicas de pesquisa promove entraves para uma maior aproximação entre os setores públicos e privados e, portanto, impedindo avanços mais sólidos da produção de pesquisa, desenvolvimento e inovação da agricultura no país.

\section{REFERÊNCIAS}

ABCSEM - Associação Brasileira de Comércio de Sementes e Mudas. 2014. $2^{\circ}$ levantamento de dados socioeconômicos da cadeia produtiva de hortaliças no Brasil. Disponível em http:// www.abcsem.com.br// Acessado em 20 de dezembro de 2014.

ANUÁRIO BRASILEIRO DE HORTALIÇAS.
2013. Santa Cruz do Sul: Editora Gazeta Santa Cruz. $88 \mathrm{p}$.

BRASIL - Ministério da Agricultura, Pecuária e Abastecimento. 2014. Registros e autorizações. Disponível em http://www.agricultura.gov.br/ vegetal/registros-autorizacoes// Acessado em 22 de dezembro de 2014.

CARVALHO SIC; BIANCHETTI LB; REIFSCHNEIDER FJB. 2009. Registro e proteção de cultivares pelo setor público: a experiência do programa de melhoramento de Capsicum da Embrapa Hortaliças. Horticultura Brasileira 27: 135-138.

CASTRO AC; CARVALHO SP; FUCK M. 2011. Regimes tecnológicos e propriedade intelectual na agricultura: o papel de novas instituições. In: CASTRO AC; POSSAS CA; GODINHO MM (eds). Propriedade intelectual nos países de língua portuguesa: temas e perspectivas. e-papers: Rio de Janeiro, 231p.

EMBRAPA - Empresa Brasileira de Pesquisa Agropecuária. 2014. Embrapa Hortaliças. Disponível em http://www.embrapa.br/ hortaliças// Acessado em 22 de dezembro de 2014.

FUCK MP; BONACELLI MB. 2011. O contexto da organização da ciência, tecnologia e inovação: evolução histórica e perspectivas futuras para o melhoramento genético vegetal no Brasil. Desenvolvimento em Debate 2: 73-89.

GRANGEIRO LC; AZEVÊDO PE; NUNES GHS; DANTAS MSM; CRUZ CA. 2012. Desempenho e divergência genética de cenoura 'Brasília' em função da procedência das sementes. Horticultura Brasileira 30: 137-142.

LSPA - Levantamento Sistemático da Produção Agrícola. 2014. Pesquisa mensal de previsão e acompanhamento das safras agrícolas no ano civil. Disponível em http://www.ibge.gov.br/ home/estatistica/indicadores/agropecuaria/ lspa// Acessado em 22 de dezembro de 2014.

MAPA - Ministério da Agricultura, Pecuária e Abastecimento. 2014. Registros e Autorizações. Disponível em http://www.agricultura.gov.br/ vegetal/registros-autorizacoes// Acessado em 22 de dezembro de 2014

MARINHO CD; MARTINS FJO; AMARAL SCS; AMARAL JÚNIOR AT; GONÇALVES LSA; MELLO MP. 2011. Revisiting the Brazilians cenario of registry and protection of cultivars: an analysis of the period from 1998 to 2010, its dynamics and legal observations. Genetics and Molecular Research 10: 792-809.

RAMALHO MAP; TOLEDO FHRB; SOUZA JC; TEIXEIRA RA. 2010. Competências em melhoramento genético de plantas no Brasil. Viçosa: ARKA Editora 104p.

SANTOS FS; AVIANI DM; HIDALGO JAF; MACHADO RZ; ARÁUJO SP. 2012. Evolution, importance and evaluation of cultivar protection in Brazil: the work of the SNPC. Crop Breeding and Applied Biotechnology S2: 99-110. 


\section{ERRATA}

Para o artigo citado abaixo, publicado no volume 34 numero 1, janeiro a março de 2016, página 19, na relação dos nomes dos autores, onde se lê "Leandro SG Azeredo", leia-se "Leandro SA Gonçalves".

GOMES GP; AZEREDO LSG; SEKIYAA; EUZEBIO MP; ROBAINA RR; MARINHO CD. 2016. Registro e proteção de olerícolas no Brasil, período de 1998 a 2014. Horticultura Brasileira 34: 019-025. DOI - http://dx.doi.org/10.1590/S0102-053620160000100003

\section{ERRATA}

We apologize for the misspelling occurred in the article cited below, published in volume 34 number 1, January to March 2016, page 19. The author's name associated to DOI was incorrectly spelled as MARINHO, GAILLT D. The correct spelling is MARINHO, CAILLET D (No artigo citado abaixo, publicado no volume 34 número 1, janeiro a março de 2016, págin 19, o nome do autor associado ao DOI foi escrito da forma incorreta seguinte: MARINHO, GAILLT D. A forma correta deve ser MARINHO, CAILLET D).

Where you read (onde se lê): MARINHO, GAILLT D

Read (leia-se): MARINHO, CAILLET D

Original citation (citação original):

GOMES GP; GONÇALVES LSA; SEKIYAA; EUZEBIO MP; ROBAINA RR; MARINHO CD. 2016. Registro e proteção de olerícolas no Brasil, período de 1998 a 2014. Horticultura Brasileira 34: 019-025. DOI - http//dx.doi.org/10.1590/S0102-053620160000100003 